\title{
In vitro Long-term Storage and Regeneration of Bulgarian Grapevine Variety "Velika" via Repetitive Somatic Embryogenesis
}

\author{
Ivan Tsvetkov", Teodora Dzhambazova, Violeta Kondakova, Rossitza Batchvarova \\ AgroBioInstitute, 8 Dragan Tsankov Blvd., 1164 Sofia, Bulgaria \\ *Corresponding Author: ivantsvetkov@abi.bg
}

Copyright $@ 2014$ Horizon Research Publishing All rights reserved.

\begin{abstract}
Somatic embryogenesis being one of the in vitro techniques that produce high regeneration rates, serves for high frequency propagation, gene transfer and germplasm storage. The aim of this work is to study the possibilities for in vitro long-term storage of grapevine genetic resources via repetitive somatic embryogenesis. Thirteen years after induction from leaves explants embryogenic cultures of Bulgarian grapevine variety "Velika" are still propagating via repetitive somatic embryogenesis in frame of clusters keeping their embryogenic and morphogenic competence. Plantlents regeneration from cotyledonary stage somatic embryos showed a normal phenotype compared with shoot-tip propagated controls. The genetic fidelity of regenerated plants was assessed by DNA analysis using Inter Simple Sequence Repeat (ISSR) markers. The amplified loci showed no differences between mother and regenerated plants, confirming the genetic authenticity of in vitro stored and propagated plants.
\end{abstract}

Keywords Grape, Somatic Embryogenesis, ISSR analysis, in Vitro Regeneration, GENRES Preservation

\section{Introduction}

In vitro techniques are a convenient tool for vine breeding to overcome the difficulties in conventional breeding studies and obtaining new cultivars. One of these techniques is somatic embryogenesis. The term of somatic embryogenesis is described as embryo formation from somatic cell or tissue. These embryos are similar to zygotic embryos formed by fertilization. Somatic embryogenesis being one of the in vitro techniques that produce high regeneration rates, serves for high frequency propagation, gene transfer and germplasm storage (Tsvetkov et al., 2005 [1]). Additionally, genotype specificity within species mainly limited the application of somatic embryogenesis as an effective tool for plant regeneration in Vitis sp. (Tsvetkov et al., 2000 [2]). Different explants have been used for the induction of grapevine somatic embryogenesis, mainly anthers/ovules, but also tissues from vegetative organs (leaves, petioles, stems, internodes) (Martinelli and Gribaudo, 2001 [3]). Several strategies have been adopted in order to keep indefinitely the embryogenic competence of the cultures and thus obtain a long-term source of somatic embryos. The maintenance of embryogenic cultures has been reported to last even for several years, retaining their embryogenic competence (Martinelli and Gribaudo, 2009 [4]). In vitro culture techniques can lead to genetic variation in plants trough somaclonal variation (Neelakandan and Wang, 2011[5]). Flow cytometry of cells of grapevine plants, regenerated via somatic embryogenesis has shown that polyploidy somaclonal variation is produced during in vitro culture (Prado et al., 2010 [6]; Acanda et al., 2013 [7]).

\section{Materials and Methods}

\subsection{Plant Material and Somatic Embryogenesis}

Embryogenic cultures from in vitro leaf tissues were established and multiplied on the base of the protocol described by Tsolova and Atanassov (1996 [8]). The 13 years storage of the repetitive somatic embryogenesis were done by periodic transfer (every 3 months) to fresh NN medium (Nitsch and Nitsch, 1969 [9]) supplemented with 2 $\mathrm{mg} / 1$ 2,4 D (2,4 dichlorophenoxyacetic acid), $1 \mathrm{mg} / 1 \mathrm{IAA}$ (indole-3-acetic acid), $1 \mathrm{mg} / 1 \mathrm{BAP}$ (benzylaminopurine) and $0,6 \mathrm{mg} / \mathrm{GA}_{3}$ (gibberelic acid) for embryo maintenance and multiplication. In vitro plantlets were regenerated on hormone-free 1/2 MS medium (Murashige and Skoog, 1962 [10]) from selected somatic embryos in cotyledonary stage of their development.

\subsection{Inter Simple Sequence Repeat (ISSR)Analysis}


Genomic DNAs were extracted from $100 \mathrm{mg}$ frozen leaf tissue following the procedure described by Murray and Thompson (1980) [11]. Ten ISSR primers were used in the analysis:

1. issr- 844/Sequence (5'-3'): CTC TCT CTC TCT CTC TRS

2. issr- CTC/Sequence (5 $\left.5^{\prime} 3^{\prime}\right)$ : CTC CTC CTC CTC $\mathrm{RC}$

3. issr- GTG/Sequence (5`-3'): GTG GTG GTG GTG $\mathrm{RC}$

4. issr- CAYC/Sequence (5'-3'): CAC ACA CAC ACA CAY C

5. BDBCA/Sequence (5'-3'): BDB CAC ACA CAC ACA CAC

6. VHVTG/Sequence (5'-3'): VHV GTG TGT GTG TGT GTG

7. SAG/Sequence (5'-3'): CCG CCG CGA TCA G

8. SAC/Sequence (5'-3'): CCG CCG CGA TCA C

9. SAGG/Sequence (5'-3'): CCG CCG CGA TCA GG

10. SACC/Sequence ( $\left.5^{\prime}-3^{\prime}\right)$ : CCG CCG CGA TCA CC

Amplification was performed in a volume of $25 \mu 1$ containing 1x PCR buffer (Fermentas, USA), 1,5 mM magnesium chloride, $50 \mathrm{ng}$ DNA, $0,4 \mu \mathrm{M}$ of each primer, $0,25 \mu \mathrm{M}$ of each dNTP and 1U Taq DNA polymerase (Fermentas, USA) in a GeneAmp ${ }^{\circledR}$ PCR System 2700 (Applied Biosystem). PCR amplification was performed with the following thermal cycles: 4 min at $94{ }^{\circ} \mathrm{C} ; 35$ cycles of denaturation $\left(30 \mathrm{~s}\right.$ at $\left.94^{\circ} \mathrm{C}\right)$, annealing $\left(30 \mathrm{~s}\right.$ at $\left.44^{\circ} \mathrm{C}\right)$ and extension $\left(2 \mathrm{~min}\right.$ at $\left.72^{\circ} \mathrm{C}\right)$, with a final step for $5 \mathrm{~min}$ at $72^{\circ} \mathrm{C}$. PCR products were separated by electrophoresis on $2 \%$ agarose gel and stained in 1x GelRed solution. The DNA was visualized with UV transilluminator and analyzed with a video image analyzer (BioImaging Systems, Cambridge, UK). Amplified fragments were scored for presence (1) or absence (0) and only strong bands were scored.

\section{Results and Discussion}

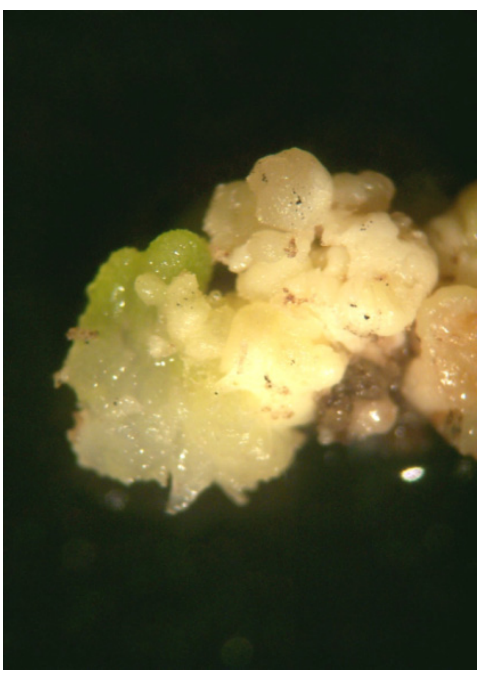

Figure 1. Primary embryogenic structure

\subsection{Somatic Embryogenesis}

Indirect somatic embryogenesis from in vitro leaf explants was obtained after 5 months induction with a rates of $78 \%$ of callus induction and 3,5\% of embryo induction. New formedsomatic embryos at early stages were removed from primary callus (Fig.1) and placed on fresh embryo maintenance medium in groups of 10 as embryogenic clusters (Fig.2). The indefinite maintenance of embryogenic culture is a crucial point of somatic embryogenesis protocol. Different methods have been attempted in order to avoid the progressive loss via necrosis as well as culture aging during subcultures (Martinelli and Gribaudo, 2009 [4]).

Our strategy was to subculture embryogenic clusters as a complete unit. Thirteen years after induction from leaves explants embryogenic cultures are still propagating via repetitive somatic embryogenesis in frame of the clusters keeping their embryogenic and morphogenic competence. It is important to note that one of the major problems of plant tissue propagation is the occurrence of phenotypic variations between the original stock material and in vitro derivate plant material. These phenotypic differences are result of somaclonal variations (Larkin and Scowcroft, 1981 [12]). In present study, all plantlets regenerated from cotyledonary stage somatic embryos (Fig.3) showed normal phenotype features, which did not manifest any deviation in comparison with the shoot-tip propagated controls (Fig. 4). After the successful regeneration from somatic embryos the plantlets were micropropagated through typical in vitro techniques which kept the phenotypic characteristics of the cultivar. However, if changes and abnormalities in morphology are not observed, that does not exclude presence of genetic variation. Moreover, grapevines are woody perennial plants and possible variations can manifest in later development stages. To assess the genetic stability and fidelity of in vitro propagated plants, obtained through somatic embryogenesis, a DNA assay was conducted.

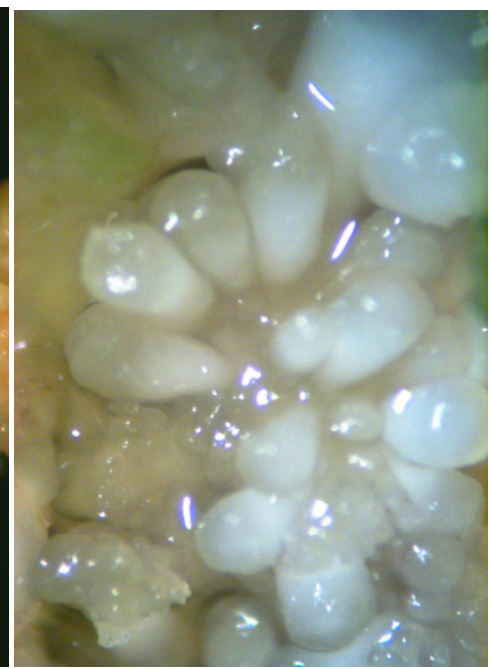

Figure 2. Embryogenic cluster 


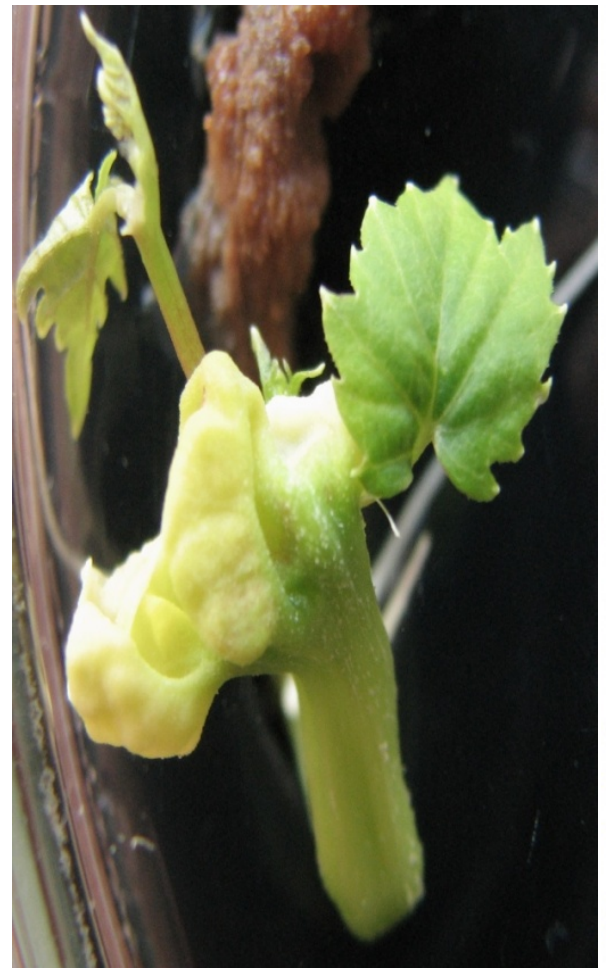

Figure 3. Germination of cotyledonary staged somatic embryo

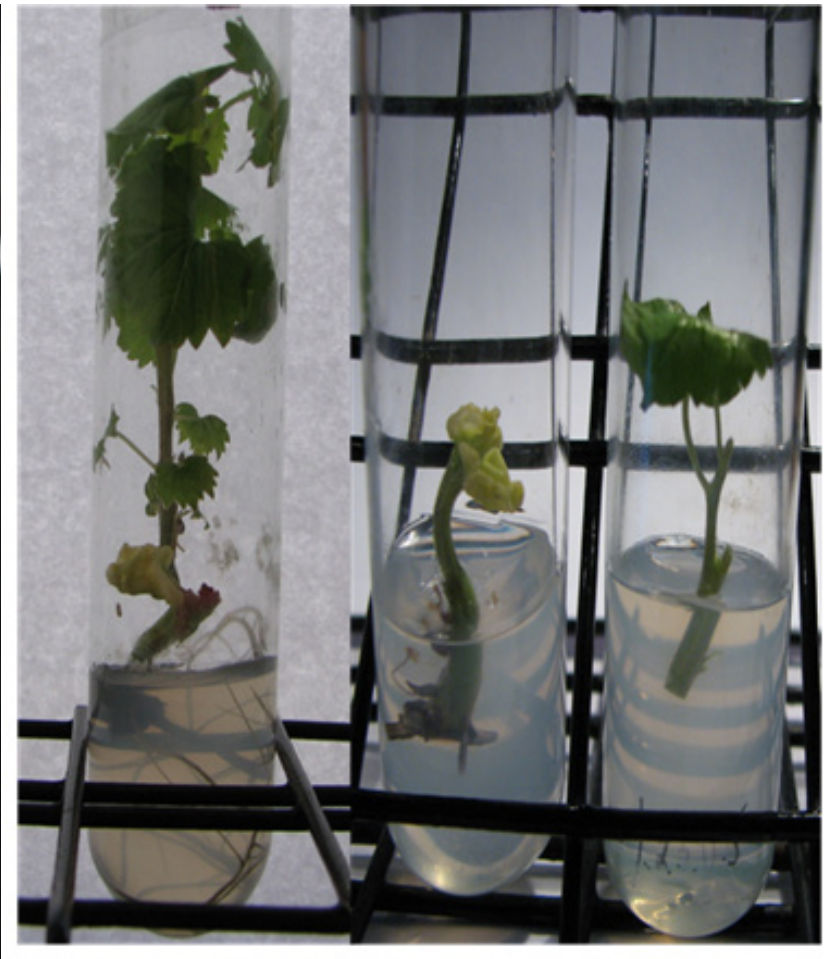

Figure 4. In vitro plantlets regeneration

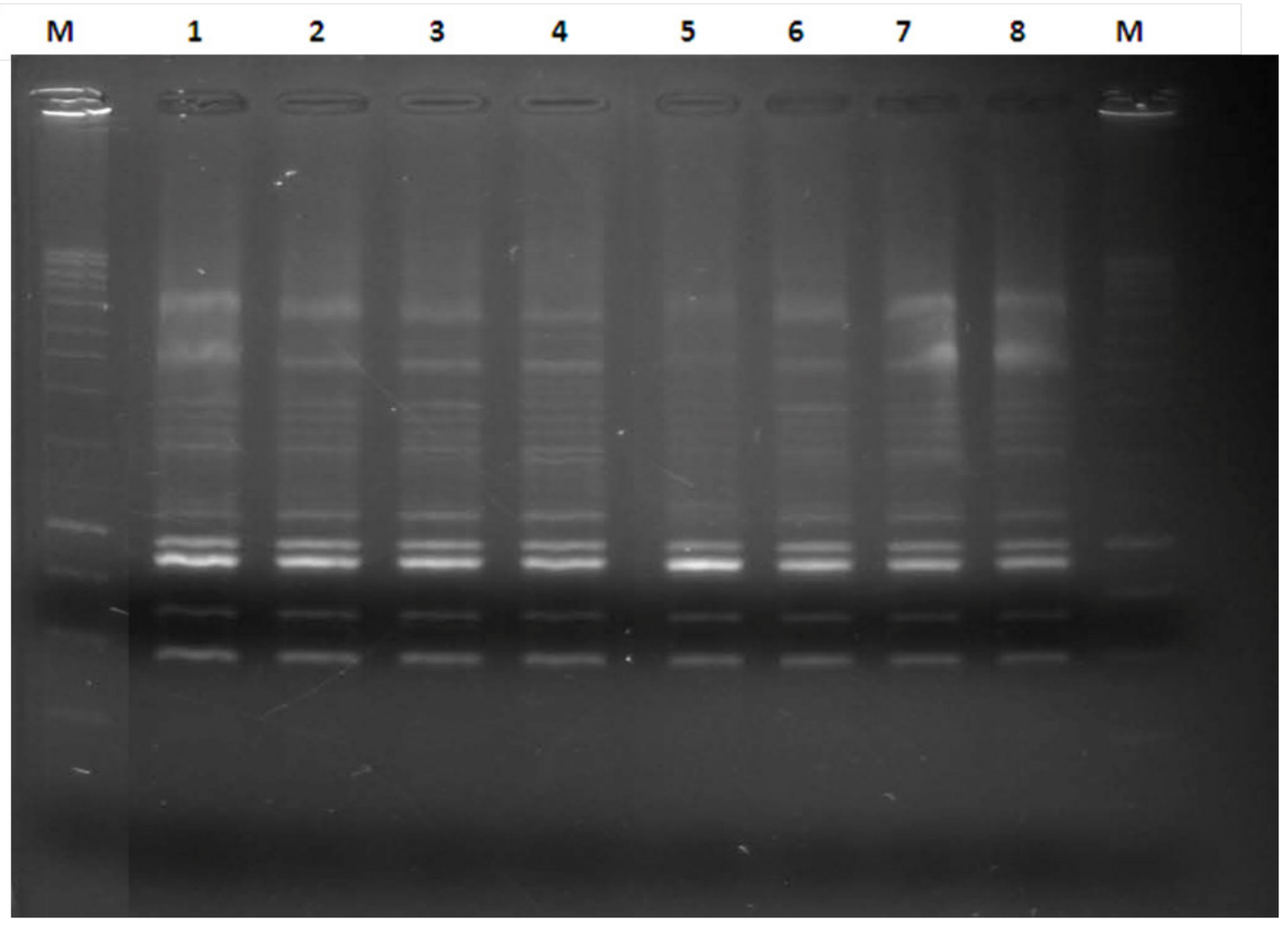

Figure 5. ISSR-profile of micropropagated plantlets obtained with SAC-primer: M- 100bp DNA ladder; from 1 to 7-plantlets regenerated from somatic embryos; 8- mother plant of cv. "Velika" (Vitis vinifera) 


\subsection{Genetic Analysis}

To perform a genetic assay we chose ISSR markers, which are one of the favored DNA marker systems for assessment of the genome stability in regenerated plants. For present DNA assay we analyzed 7 randomly chosen in vitro propagated plantlets and the original stock material of $\mathrm{cv}$. "Velika" with 10 ISSR primers. All primers amplified successfully and generated fingerprinting profiles for the analyzed samples based on distinct reproducible amplification products. Every ISSR-primer produced a fingerprint profile, which showed to be identical for all analyzed samples (Fig. 5).

So far, ISSR analysis has been successfully applied to study the genetic stability of micropropagated plantlets of different crops (Martins et al., 2004 [13]; Alizadeh et al., 2008, 2009 [14,15]). Present results show that the ISSR-profile of all analyzed regenerants matches the profile of the original mother plant cv. "Velika". None of the primers showed polymorphism in the analyzed set of plants which confirmed the fidelity of regenerated plantlet population to the genotype of mother plant. Present study showed that the long term storage of somatic embryos and the in vitro propagation did not cause variation in phenotypic and genetic make-up of regenerated plantlets. Additionally, ploidy evaluation with a technique such as flow cytometry of somatic embryogenesis-regenerated plants is recommended to assure trueness-to-type.

\section{Conclusions}

The long term storage of grape somatic embryos under the described protocol did not affect the competence of embryos and the genetic fidelity of regenerated plantlets and therefore can be successfully applied for propagation, gene transfer and germplasm storage of grapes.

\section{REFERENCES}

[1] Tsvetkov I., Atanassov A., Jankulova M., Vulchev V., Todorov I., Pandeliev S., Katerov K., Atanassov I., Hvarleva T., Tsvetkov Y., Genov I., Dzambazova T., Antonov I., Marinov L., Dimitrov E., Panamska M., Varadinova G., Slavova K., Atanassov I., Shishmanov G., Ivanova N. and Laginova M., 2005. Grapevine Plant Genetic ResourcesImprovement, Preservation and Biodiversity. Biotech \& Biotech Eq, 19: 13- 21.

[2] Tsvetkov I., Tsolova V. and Atanassov A., 2000. Gene transfer for stress resistance in Grapes. Acta Horticulturae, 528: 389-394.
[3] Martinelli L. and Gribaudo I., 2001. Somatic Embryogenesis in Grapevine. In: Molecular Biology and Biotechnology of the Grapevine, K.A. Roubelakis-Angelakis (Ed.), Kluwer Academic Publishers, The Netherlands, ISBN 0-7923-6949-1, 327-351.

[4] Martinelli L. and Gribaudo I., 2009. Strategies for effective somatic embryogenesis in grapevine: an appraisal. In: Roubelakis-Angelakis KA (ed.) Grapevine molecular physiology and biotechnology, 2nd edn. Springer, Dordrecht, 461-493.

[5] Neelakandan A.K. and Wang K., 2011. Recent progress in the understanding of tissue culture-induced genome level changes in plants and potential applications. Plant Cell Rep, 31:597-620.

[6] Prado M.J., Rodríguez E., Rey L., González M.V., Santos C. and Rey M., 2010. Detection of somaclonal variants in somatic embryogenesis-regenerated plants of Vitis vinifera by flow cytometry and microsatellite markers. Plant Cell Tissue Org Cult, 103:49-59.

[7] Acanda Y., Prado M., Gonzales M. and Rey M., 2013. Somatic embryogenesis from stamen filaments in grapevine (Vitis vinifera L. cv Mencia) and changes in ploidy level and DNA nuclear content. In vitro cellular and Developmental Biology- Plant, Springer- Verlag (ed.), DOI: 10.1007/s11627-013-9499-7.

[8] Tsolova V. and Atanassov A., 1996. Plant Regeneration of Vitis sp. via repetitive embryogenesis. Biotechnol. \& Biotechnol. Eq., 1: 32-36.

[9] Nitsch J.P. and Nitsch C., 1969. Haploid plants from pollen grains. Science, 163:85-87.

[10] Murashige T. and Skoog F., 1962. A revised medium for rapid growth and bioassays with tobacco tissue cultures. Physiol Plant, 15:473-497.

[11] Murray M. and Thompson W., 1980. Rapid Isolation of high molecularweight plant DNA. Nucl. Acids Res., 8: 4321-4325.

[12] Larkin J.P. and Scowcroft W.R,, 1981. Somaclonal variation - a novel source of variability from cell cultures for plant improvement. Theor Appl Genet., 60: 197-214.

[13] Martins M., Sarmento D., and Oliveira M.M., 2004. Genetic stability of micropropagated almond plantlets as assessed by RAPD and ISSR markers. Plant Cell Rep, 23: 492-496.

[14] Alizadeh M., Singh S.K., Tripta J. and Sharma T.R., 2008. Inter simple sequence repeat analysis to confirm genetic stability of micropropagated plantlets in three grape (Vitis spp.) rootstock genotypes. J Plant Biochem Biotech, 17: 77-80.

[15] Alizadeh M. and Singh S.K., 2009. Molecular assessment of clonal fidelity in micropropagated grape (Vitis spp.) rootstock genotypes using RAPD and ISSR markers. Iranian J Biotech, 7 (1): 37-44. 